\title{
Social representations and food practices of people with Diabetes Mellitus Type 2
}

\author{
Maria Marta Amancio Amorim ${ }^{*}$, Alessandra Hugo de Souza ${ }^{2}$, Natália Ramos ${ }^{3}$ and Maria Flávia Gazzinelli ${ }^{4}$ \\ ${ }^{1}$ Researcher, Center for Studies of Migration and Intercultural Relations, Lisbon, Portugal \\ ${ }^{2}$ Nutricionist Specialist in Geriatric Nutrition, Master student in the Graduate Program in Vertebrate Biology-PUC Minas, Brazil \\ ${ }^{3}$ Professor, Open University of Lisbon, Center for Studies of Migration and Intercultural Relations, Lisbon, Portugal \\ ${ }^{4}$ Professor, The School of Nursing at Federal University of Minas Gerais, Belo Horizonte, Brazil
}

\section{Introduction}

Type 2 diabetes mellitus (DM2) is a chronic disease characterized by inadequate insulin levels resulting in hyperglycemia [1]. Due to the requirement of constant glycemic control, chronicity and lack of cure, the person with DM2 remains linked to the health system for decades and needs continuous attention focused on the integral care provided by family health, actions to promote, monitor and prevent complications of DM2 [2]. The complexity of caring for people with DM2 requires an interdisciplinary approach with health professionals open to dialogue and willing to plan consultations and interventions appropriate to the specific needs of people with DM2 focused on self-care and glycemic control actions.

To reduce glycemic levels and avoid complications of the disease, self-care practices such as healthy eating, exercise and medication should be adopted [1]. Self-care is not an easy task for most people with DM 2. When they discover the disease, they experience ruptures in their identity $[3,4]$ and in the behaviors adopted before the disease, especially with regard to diet [5]. The identification of the limiting aspects and the unique way in which people articulate different aspects that interact in the production of self-care and in glycemic control is favored by the knowledge of the subjectivity and the meanings attributed to them by the disease.

The subjectivity is permanently committed to the subject's actions in the different spaces in which he participates [6]. The subjectivity is articulated with the social representations, "a complex subjective production that simultaneously is constituted in the individual and social subjectivity".

One of the ways to deepen the knowledge of the subjective view of the person with DM 2 is to seek their social representations. Social representation is the mental construction of reality, which enables the understanding and organization of the world, as well as guides the behavior of people [7].

The disease studied, DM2, is an object of social representation, since "the peculiar and threatening nature of the disease responds by its extreme capacity to generate representations" [8]. It is from the social representations of those who suffer the disease that the very meaning of their experience will be established, which in turn will guide their behavior, a principle that guided the choice of people with DM2 as the social subject of the social representations to be studied.

The purpose of this study is to present studies that address the social representations of people with type 2 diabetes in relation to disease and diet to understand the health education actions of this disease.

\section{Social representations of people with type 2 diabetes in relation to the disease}

In relation to DM2 some studies were conducted using the social representations referential. As DM2 is a disease involving different aspects, the authors cited in this review delimitated the parts of the research object to be studied, in agreement with the thought of Sá [8]. According to this author it is necessary to simplify the complex phenomenon of social representations so that it becomes comprehensible by the foundation of the theory of social representations and define it based on the purpose of the research, which selects and delimits the dimensions or aspects of the phenomenon to be studied.

Torres-López, Sandoval-Diaz and Pando-Morineo [9] studied the social representations of Mexicans on DM2 using the ethnographic approach. For these people with economic limitations, affective and family problems, DM2 is an expression of bodily sensations, pain, images and meanings of their own. They reported difficulties in eating properly and practicing physical activity in the large city in which they live.

Péres, et al. [10,11] identified the social representations of women with DM2 from the popular strata in relation to the health-disease process. DM2 is related to negative feelings such as shock, revolt, sadness; the diet is linked to loss of pleasure and damage to health and medication is perceived as tiring and at the same time as a promoter of well-being.

Barsaglini [12] analyzed the social representations and experience of men and women with DM2, articulating the symbolic dimension, based on the meanings and the meaning attributed to the disease and the concrete dimension of its management, in a socio-anthropological approach. The ways in which these people think and deal with illness involve structural, symbolic, context of everyday life, subject biography, previous, current, personal, and other experience, and the course of illness itself.

${ }^{*}$ Correspondence to: Maria Marta Amancio Amorim, Researcher, Center for Studies of Migration and Intercultural Relations, Lisbon, Portugal, E-mail: martamorim@hotmail.com

Received: April 17, 2019; Accepted: May 09, 2019; Published: May 13, 2019 
Regarding the care and treatment that DM2 requires, some studies were conducted using the social representations framework. Sales, Damasceno and Paiva [13] studied the social representations of people with DM2 on care, using the structural approach. The structure of social representations of care has as its central core affective aspects and, as a peripheral system, cognitive elements. Santos, et al. $[14,15]$ identified the social representations of people with DM2 about perceived family support in relation to treatment. These people recognized family support as a relevant factor for treatment; but they also pointed out that the excessive control exerted by the relatives restricts their autonomy and awakens ambiguous feelings.

Amorim, et al. $[16,17]$ investigated the construction of the identities representations of users with DM2 of primary health care and their relation with the required self-care actions. The interactions mediated by the identity processes - social comparison, social attribution and categorization in the studied group, provided the social construction of the identity's representations "normal", "accepting the disease", "being dissatisfied", "having difficulties" of participants with DM2.

These studies contribute to the understanding that DM2 is an object that generates social representations. People with DM2 value the psychosocial needs of family care and support in conducting treatment. Health professionals should understand the context permeated by the subjective sense of people with DM2 altered by the disease, in addition to the biomedical point of view. People with DM2 on discovering the disease experience disruptions in identity and behavior. People with DM have their own meanings and negative feelings about the disease that can become obstacles to self-care, especially in relation to diet, one of the aspects of DM2 that have a strong impact on self-care and glycemic control since people with DM2 receive the diagnosis of the disease, subject to be approached next.

\section{Social representations of the diet of people with type 2 diabetes mellitus}

Research investigating the social representations of food was not found in the literature. However other qualitative research approaches were employed. Péres, Franco and Santos [18] apprehended the thoughts, feelings and behaviors regarding the diet of women with DM2. These people report difficulty in following the prescribed food plan, due to the different meanings associated with them, such as loss of the pleasure of eating and drinking, autonomy and freedom to feed themselves.

Pontieri and Bachion [19] analyzed the health beliefs of people with DM2 regarding nutritional therapy and its influence on adherence to treatment. The discourses reveal restrictive beliefs about food that act as a barrier to the implementation of the food plan. These beliefs must be known by health professionals, as they influence adherence to DM2 treatment.

Santos and Araújo [14] characterized the difficulties found for changes in dietary practices of people with DM2 seen at a high complexity outpatient clinic. The fact that health professionals do not understand food practices in their multidimensionality makes it difficult to relate to people who do not adhere satisfactorily to the food plan. Cultural and affective values and economic limitations also interfere with adherence to treatment.

These investigations contribute to a re-dimensioning of the health professionals' performance in order to improve the practices regarding self-care and glycemic control, taking into account health beliefs, cultural factors, attitudes and feelings of people with DM2.
Studying food through the referential of social representations means understanding that the person, in his / her social and cultural context, also chooses the foods to make up his food according to his subjective aspects, the way he thinks he is correct and the way he translates the transmitted guidelines by health professionals. Social representations of food are an orientation to action insofar as they shape and constitute the elements of the context in which a behavior occurs [7].

Food is a complex concept that begins with food selection [20]. Selection is a set of conscious and unconscious decisions made by a person at the time of purchase and / or food consumption [21], being dependent on the objective aspects such as physical and financial accessibility and subjective aspects such as desires and needs, triggered by odor, taste, sight and hearing [22].

The subjective senses of food taste and taste are constantly emphasized in stories of food symbolism in literature, religion, culinary arts, history and cinema [23]. In anthropology, eating is a socially, culturally constituted act, from which each person establishes a subjective and proper relationship with the foods to be consumed [24-28]. In sociology, food is seen as a social practice built throughout life and characterizes what people eat, being a constituent of their identity, according to the postulate "we are what we eat." Food is a constructor of collective identity in a dynamic game of similarities and differences $[29,30]$. In the psycho-sociological view, when eating, man is incorporated and integrated into a cultural space [31].

At the present time, food is an indispensable self-care practice in improving the quality of life of the population, as evidenced by its protective factor of health. Understanding the diet that people practice as a subjective, cultural and social concept is one of the great challenges for health professionals.

The theory of social representations helps to understand the meanings created by people with DM2, since, according to Wachelke and Camargo [32], social representations are references to the perception of subjective norms by these people as social subjects. The subjective norms concern the person's perception of the social pressure he or she suffers to adopt or not to adopt behavior [33].

The lifestyles adopted by the population in general do not always meet a healthy diet; because these styles can be determined by beliefs and attitudes generated by knowledge that can be produced by social representations [34]

In the literature of social representations, the relation between representations and social practices is proven. For Vala [35] social representations are guiding practices and behaviors are classified into representational and situational. Representational behaviors are determined at least by the concrete situation in which they occur and at most by pre-situational factors that reveal the level of attitudes and representations. In situational behaviors, the characteristics of the moment and not of the social representations are more salient and direct the behavior.

Jodelet [36] states that social representations determine the practices of the mentally ill. Similarly, for Brito and Camargo [34], health representations influence the health care behaviors of individuals.

Rouquete [37] argues that social practices and representations are in correlation. Differently, for Campos [38] representations and practices interact in a circular relationship that makes it difficult to identify a causal relationship. 
For Wagner [39], the representation does not explain the occurrence of the practice. The practice is part of the representation, thus composing a relation of the complex representation-action.

Given the different ways scholars express the relationship between social representations and practices, Amorim, et al. [24,25] have chosen to treat eating practices as part of the food representation of people with $\mathrm{DM} 2$, thus configuring a complex representation-action.

The choice of Wagner's thinking to analyze these data together was based on the consonance found between the social representations of the diet of people with DM2 and the dietary practices they declared. It is highlighted that the alimentary practices of these people exceed the representational thought of the food for describing actions carried out in the daily life. It is assumed that people's practices and behaviors cannot be explained solely by their thinking, since there are other sociocognitive aspects that interact to produce these behaviors and practices [32]. Thus, in the study by Amorim, et al. [24,25] when mention is made of social representations of food, refers to social representations and practices related to food.

In order to collect the thoughts of people with DM2 on the diet of diabetics and their eating habits, Amorim, et al. [25,26] considered Jodelet's orientations - to study social representations and practices "to avoid working on floating social discourse, without a seat or reference to practice" [40].

The objective of the study by Amorim, et al. [24,25] was to identify the social representations about the diet of people with DM2. As a result, some respondents indicated that the person with DM2 should eat healthily. Others relied on the quality of food, representing it as "eating vegetables and fruits" and "avoiding sweets." There are still those whose speech was based on eating little, worrying about the quantities of food eaten. There are those who represented eating as not eating too much, focusing on the frequency of feeding, as they consider that breaking down the food in many meals is not appropriate. Others focused their speech on selective food intake, specifically those that do not harm the body. Finally, others considered that food does not imply following a specific diet. Different discourses approaching dietary norms can be found in society, leaving the person with DM2 in doubt about the foods they can or cannot eat.

Specifically, Ribas [41] identified the social representations about the food of people with DM2, not evaluating their eating practices. The discourses around the food of people with DM2 have been permeated with diverse feelings such as depression, inferiority, anxiety, safety, comfort, desire and addiction, which may become obstacles to the follow-up of the prescribed diet plan.

In another study by Amorim, et al. [26] the relationship between identity representations, social representations of the diet of people with DM2 and their glycemic control was analyzed. The values of glycate hemoglobin were used to analyze the relationship between identity representations and social representations of diet and glycemic control. Normal participants state that they eat healthy, eat little, eat vegetables, and divert from sweets. They have positive attitudes of health accountability that lead to healthy eating practices and contribute to normal blood glucose. Not eating too much, not eating at all and skipping candy is the way the participants who accept the disease represent their food. They expect, from health professionals, the conduct of treatment and, from God, the cure of DM2, attitudes of non-health accountability that lead to inadequate dietary practices leading to glycemic control. Participants with difficulties represent eating in not eating at all, not eating too much, not following the diet and eating vegetables and fruits. The behaviors and attitudes of these participants who have difficulty in revealing their identity and taking care of themselves result in inadequate glycemic control. Nonconforming participants report not eating too much, not eating at all and eating vegetables and fruits. They focus on unfavorable and negative attitudes, the difficulties of accepting DM2, the dietary restrictions that led to unhealthy eating practices, and the consequent lack of glycemic control. Some participants, who accept the disease, have difficulties and nonconformists have normal blood glucose because they perform healthy eating practices. Identity representations and social representations of food produce healthy or unhealthy eating practices that contribute to the participants' glycemic control or lack of control. The obstacles encountered in self-care actions by participants who think that they accept the disease, think they are unhappy and have difficulties should be understood by the multidisciplinary health team that works in primary health care.

\section{Final considerations}

The way in which people with DM2 understand their illness and act on their self-care is defined from the representations they make about the social objects that disturb them and that surround their environment, especially their diet and their identity.

People with DM2 have taken from their social reality elements capable of giving body and consistency to their social representations. In this sense, social representation is an essential element to be considered in the work of prevention and health promotion of people with diabetes. Thus, health education for people with DM2 cannot be restricted to the dimension of the transmission of knowledge and should be established as a device of subjective change.

In order to make this presuppose, health education must offer opportunities for the discourses constructed by its participants to be re-elaborated, assuming new meanings, what happens when they can think what they had not yet thought, attributing new meanings to the representations elaborated on them and on the social environment.

Thus, health professionals should listen to people with DM2 to understand how they understand the care they develop. To penetrate these meanings attributed by the subjects to food, disease and themselves is essential for an educational action to have an impact in terms of the adoption of self-care practices.

Still in this context, there are guidelines on "no" food practices that must be rethought in order to point out more affirmative orientations, since we have the knowledge that the emotional aspect that the participants associate with affective perception has profound implications in the how they take care of themselves and ensure selfcontrol.

These considerations, taken as a whole, point to the need to change educational practices aimed at groups of people with DM2 who are currently hegemonic. Although it is now possible to observe new orientations in health education that are changing, it is important to emphasize that the traditional model of education is still what prevails.

The traditional model of health education is based on an understanding of health as absence of disease and on the proposition of educational strategies guided by biomedical assumptions. In this context, health education actions are persuasive, as they seek to prescribe certain behaviors considered ideal for disease prevention. The traditional approach to health education is also characterized by the identification of health professionals as legitimate executors or agents that define educational actions in health. 
According to this view, because health professionals are those who know the healthiest choices, they are empowered to convince people to adopt a lifestyle that is compatible with these choices. The possibility of choosing autonomously for attitudes considered unhealthy, after having participated in some type of health educational activity, is interpreted by professionals as a failure to conduct these actions. Moreover, in traditional health education, choices considered healthy by health professionals are proposed as the only possible options available to people, disregarding the values and meanings on which these people rely to guide their lives.

However, it is known that man exercises his will in the choice between what, how much and when to eat. The process of perceiving, thinking, and expressing meanings in "food you can eat" or "food you cannot eat," "eat little" or "eat too much," "eat everything," or ", "Following the diet" or "not following the diet" has its starting point in the human being's ability to make distinctions and directs people's eating practice for many years.

On the other hand, it is observed that the need for an approximation with extended frameworks has resulted today in educational actions in health that take into account the complexity of the health phenomenon and the complexity of the subject that seeks this health. What is still missing in these approaches is the creation of pedagogical devices that focus not only on the cognitive and intellectual dimension of learning, but also on their affective dimension, responsible for the production of new modes of subjectivities.

It is important to highlight that it is accepted that meeting these principles is a challenge for health professionals, considering that the statements of people who participate in health education, such as the people of the present study, are not linear, they are not responses that lead to directly to the identification of the subjective senses that underlie these statements. In the understanding of the subjectivity in which these people are situated, the subjective configuration represents a very complex system of subjective senses that can result in very diverse and even ambiguous and contradictory thoughts and actions.

Faced with this challenge, it is important to emphasize that even if changes in the health education scenario are admitted today, especially in the epistemological field, these changes have not translated into practices that use the social representations of people with some illness as a theoretical orientation.

\section{References}

1. Sociedade Brasileira de Diabetes (2017) Gomes BM, Lerario AC (Eds) Oliveira JEP, Montenegro Junior, RM, Vencio S (Org) Guidelines of the Brazilian Society of Diabetes, 2017-2018. São Paulo, Brasil.

2. Brasil. Ministério da Saúde (2009) National strategy for health education for self-care in diabetes mellitus. Florianópolis, SEAD/UFSC, Brasil.

3. Bury M (1982) Chronic illness as biographical disruption. Sociology of Health \& Illness 4: 167-182.

4. Williams SJ (2000) Chronic illness as biographical disruption or biographical disruption as chronic illness? Reflections on a core concept. Sociology of Health \& Illness 22: 40-67.

5. Cyrino AP (2009) Between science and experience - a mapping of diabetes self-care. Editora UNESP, São Paulo, Brasil.

6. Rey FLR (2009) The social in psychology and social psychology. ( $2^{\text {nd }}$ Edn) Petrópolis: Vozes.

7. Moscovici S (2004). Representações sociais - investigações em psicologia social. (2nd Edn) Petrópolis: Vozes.

8. Sá CP (1998) The construction of the research object in social representations. Rio de Janeiro (Ed) UERJ.
9. Torres-López TM, Sandoval-Diaz M, Pando-Morineo M (2005). Sangre y azúcar: representaciones sobre la diabetes de los enfermos crónicos en un barrio de Guadalajara, México. Cad. Saúde Pública 21: 101-110.

10. Péres DS, Franco LJ, Santos MA (2008) Health representations in women with type 2 diabetes. Ciência, Cuidado e Saúde 7: 295-303.

11. Péres DS, Franco LJ, Santos MA, Zanetti ML (2008) Social representations of diabetic, grassroots women in relation to the health-disease process. Rev. Latino-Americana Enfermagem 16: 389-395.

12. Barsaglini RA (2011) Social representations and experience with diabetes: a socioanthropological approach. Rio de Janeiro, Fiocruz, Brasil.

13. Sales ZN, Damasceno M, Paiva MS (2007) Structural organization of social representations of care. Rev. Saúde Com 3: 28-26.

14. Santos AFL, Araújo JWG (2011) Food practice and diabetes: challenges for health surveillance. Epidemiolog Serv Saúde 20: 255-263.

15. Santos, MA, Alves RCP, Oliveira VA, Ribas CRP, Teixeira CRS, et al. (2011) Social representations of people with diabetes about perceived family support in relation to treatment. Rev Esc Enferm USP 45: 651-658.

16. Amorim MMA, Ramos N, Brito MJM, Gazzinelli MF (2014) Identity representations of people with diabetes. Qual Health Res 24: 913-922.

17. Amorim MMA, Ramos N, Gazzinelli MF (2016 a) Identity representation of users with diabetes mellitus in primary care. Psicologia, Saúde \& Doenças 17: 45-51.

18. Food-based dietary guidelines (2006) Food and agricultural Organization Food guide for the Brazilian population. Promoting healthy eating. FAO.

19. Pontieri FM, Bachion MM (2010) Beliefs of diabetic patients about nutritional therapy and its influence on treatment adherence. Ciência \& Saúde Coletiva 15: 151-160.

20. Philippi ST (2003) Nutrition and dietary technique. Barueri: Manole.

21. Hamilton J, McIlveen H, Strugnell C (2000) Educating young consumers - a food choice model. Journal of Consumer Studies \& Home Economics 24: 113-123.

22. Drewnowski A (1999) Palatability and satiety: models and measures. Taste and satiety. Anais Nestlé 57: 35-46.

23. Garcia RWD (1994) Social representations of food in the urban environment: some considerations for the study of the symbolic aspects of food. Rev Cad Debate 2: 12-24.

24. Amorim MMA, Ramos N, Gazzinelli MF (2016 b). Social Representations of Feeding People with Type-2 Diabetes Mellitus. J Endocrinol Diab 3:1-9.

25. Amorim MMA, Ramos N, Gazzinelli MF (2018 a) Food in the Vision of People with Diabetes Mellitus: Contribution of Social Representations. Psychology, Community \& Health 7: 97-108

26. Amorim MMA, Ramos N, Gazzinelli MF (2018 b) Social representations of people with diabetes mellitus: implications in glycemic control. Psic., Saúde \& Doenças 19 293-309.

27. Ramos M, Stein LM (2000) Development of infant food behavior. Jornal de Pediatria 3: 229-237.

28. Mintz SW (2001) Food and Anthropology - A Brief Review. Revista Brasileira de Ciências Sociais 16: 31-41.

29. Fischler C (1988) Food, self and identity. Social Science Information 27: 275-292.

30. Mintz SW (2008) Food, culture and energy. Clio Série Revista de Pesquisa Histórica 2: $13-35$.

31. Poulain J (2004) Sociologies of food - eaters and social food space. Florianópolis, Ed. UFSC, Brasil.

32. Wachelke JFR, Camargo BV (2007) Social representations, individual representations and behavior. Rev Interamericana de Psicologia 41: 379-390.

33. Ajzen I, Fishbein M (1980) Understanding attitudes and predicting social behavior Englewood Cliffs, Prentice Hall, NJ.

34. Brito AMM, Camargo BV (2011) Social representations, beliefs and health behaviors: a comparative study between men and women. Temas em Psicologia 19: 283-303.

35. Vala J (2006) Social representations and social psychology of everyday knowledge. In: Vala J, Monteiro MB (Eds) Psicologia social ( $7^{\text {th }}$ Eds) Lisboa: Fundação Calouste Gulbenkian p. 457-502.

36. Jodelet D (1989) Folies et Represéntations Sociales Paris: PUF.

37. Rouquette ML (2000) Representations and social practices: some theoretical elements In: Moreira ASP, Oliveira DC (Eds) Estudos interdisciplinares de representação social. (2nd Eds) Goiânia p. 39-46. 
38. Campos PHF (2003) The structural approach and the study of the relations between practices and social representations. In: Campos PHF, Loureiro MCS (Eds) Representações sociais e práticas educativas. Goiânia: UCG, p. 22-36.

39. Wagner W (1994) Description, explanation and method in researching social representations. In: Guareschi PA, Jovchelovitch S (Eds) Textos em representações sociais. ( ${ }^{\text {rd }}$ Edn) Petrópolis, Brasil: Vozes, p. 149-186.
40. Jodelet D (1986) Fou et folie dans un milien rural française: une approche monographique. In: Doise W, Palmonari A (Orgs) L`Etude des Represéntations Sociales. Neuchàtel: Delachaux et Niestlé 171-192.

41. Ribas CRP (2009) Social representations of foods for people with type 2 diabetes mellitus. Ribeirão Preto, Brasil: Escola de Enfermagem, Universidade de São Paulo.

Copyright: ${ }^{0} 2018$ Amorim MMA. This is an open-access article distributed under the terms of the Creative Commons Attribution License, which permits unrestricted use, distribution, and reproduction in any medium, provided the original author and source are credited. 